\title{
The Contribution of Computer-Supported Collaborative Learning to the Development of Collaboration Between Students: Results of Pilot Implementation in Greek Secondary Education
}

\author{
Vassilios Giannakos ${ }^{1} \&$ Maria Darra ${ }^{2}$ \\ ${ }^{1}$ Med Education Sciences, Athens, Greece \\ ${ }^{2}$ Department of Primary Education, University of the Aegean, Rhodes, Greece \\ Correspondence: Maria Darra, Assistant Professor, University of Aegean, Dimokratias 1, 7th March Building, \\ 85100, Rhodes, Greece.
}

Received: October 19, 2018

Accepted: November 28, 2018

Online Published: February 26, 2019

doi:10.5539/ies.v12n3p158

URL: https://doi.org/10.5539/ies.v12n3p158

\begin{abstract}
The main purpose of this survey is to explore whether Computer-Supported Collaborative Learning (CSCL) constitutes a good practice in the teaching of Literature in Lyceum and in the cross-curricular approach of the specific subject. More specifically, the contribution of the digital platform web 2.0, wiki pbworks - along with the use of subsidiary software applications - is explored in the promotion of collaborative learning and the special skills it develops among students. The method that was used is the field experiment, working both with an experimental group ( 25 students) and with a control group ( 25 students). The outcome of the findings, regards the promotion of collaborative learning, the formation of a more positive attitude towards collaboration proved to be successful with regard to the use of Computer-Supported Collaborative Learning and the application of the digital platform of collaboration web 2.0, wiki pbworks.
\end{abstract}

Keywords: CSCL, web 2.0, wiki, ICT, literature

\section{Introduction}

Computer Supported Collaborative Learning (CSCL), which is an evolution of educational technology and is based on the social theories of social constructivism and socio-cultural theories (Koschmann, 1996), has been implemented in the last few years, through the use of web 2.0 applications.

In the field of education today, CSCL has made its presence felt, and so far, surveys show that its use can bring particularly positive results to the learning process. Examples of such investigations are those of $\mathrm{Fu}$, $\mathrm{Chu} \& \mathrm{Kang}$ (2013) who reviewed a web 2.0 platform (wiki) as a computer-supported collaborative learning environment (CSCL) in the final grade of basic education. Also, Wang's research (2014), which investigated whether collaborating on a wiki can contribute to both language development and social interaction, thus emphasizing the potential of CSCL, as well as the research by Jeong, Hmelo-Silver, Jo, and Shin (2016), which is a meta-analysis of the research on the application of the CSCL method to STEM (Science, Technology, Engineering and Mathematics) education.

In the Greek educational reality, surveys carried out are smaller in number and limited in range. They mainly relate to the exploration of the potential of a web 2.0 platform (wiki) in the creation of science simulation programs, the use of the same platform in e-learning, its influence in learning through two organized activities, synthetic work and web collaboration (Altanopoulou, 2011; Chouliara, Frentzou-Rodokanaki, \& Antoniou, 2011; Mitala, 2008; Roussinos \&Tzimogiannis, 2011; Syvaka \& Ginoudi, 2013). However, there are very few studies in Greece concerning the use of CSCL during the educational process in the classroom (Geomelou, 2015; Karystinakis, 2012).

There is, therefore, relatively little research into the contribution of ICT in the educational process through the use of CSCL. Especially in Greece, it doesn't revolve around language courses. This study aims to fill this gap as it involves applying the CSCL method to a language course within the classroom. The results given throughout its course will highlight an alternative aspect of the use of technology in the educational process. Hopefully, it will encourage researchers to explore its further use in other teaching subjects and to inform teachers about new 
possibilities of technology in education so as to be motivated to optimize it.

\section{Review of Relative Studies}

In the extensive literature of this study, there can be found 31 researches related to the use of the wiki platform at all levels of education. Most of them were conducted in university departments and, therefore, concern the use of the platform by university students, as the participants were more likely to be able to use it, since their age allowed them to have the required knowledge and the universities had the necessary equipment. They also had the necessary experience and maturity to be able to collaborate. The main outcomes of these surveys are summarized below (Kyrtsoglou, 2009).

Studies on the impact of a web 2.0 platform on students' attitudes towards collaboration, have demonstrated that the group using the wiki platform had a significantly better attitude towards collaboration than students in the comparison group (Altanopoulou, 2011; De Wever, Hämäläinen, Voet, \& Gielen, 2015; Karystinakis, 2012; Rick, Guzdial, Holloway-Attaway, \& Walker, 2002), that the wiki platform encourages a more cooperative lesson, approaching a constructive learning model (Kyrtsoglou, 2009; Mitala, 2008; Ruth \& Houghton, 2009; Wang, 2014) and that it provides educational, technological and social possibilities for collaborative learning among students (Avci \& Askar, 2012; Cho \& Lim, 2017; Chouliara et al., 2011; De Wever et al., 2015; Fu et al., 2013; Golikidou \& Tzimoyiannis, 2014; Manios, 2014; Mitala, 2008; Pozidis, Manousou, \& Koutsouba, 2015; Roussinos \& Tzimoyiannis, 2011; Wang, 2014), but also that different types of collaboration require different kinds of technological support, depending on the level of education (Syvaka \& Ginoudi, 2013; Wang, 2014). Students' attitudes towards the educational value of the wiki platform are positive and there is an increase of participation (Avci \& Askar, 2012; Cho \& Lim, 2017; Fu et al., 2013; Karystinakis 2012; Roussinos \& Tzimoyiannis, 2011; Wang, 2014).

At the same time, it was found that collaboration on a wiki platform can contribute to both language development and social interaction (Jeong et al., 2016; Wang, 2014), pointing out the possibilities of computer-supported collaborative learning (CSCL) (Wang, 2014) in distance learning (Elgort, Smith, \& Toland, 2008; Syvaka \& Ginoudi, 2013) and the sharing of knowledge (Elgort et al., 2008; Hemmi, Bayne, \& Land, 2009; Kear, Woodthorpe, Robertson, \& Hutchison, 2010; Ruth \& Houghton, 2009). Furthermore, the wiki platform increases the degree of commitment among student as well as cognitive engagement, mainly in tertiary education, and classroom monitoring (Karystinakis, 2012; Neumann \& Hood, 2009), while it is considered useful, flexible, as it promotes originality and problem-solving ability (Geomelou, 2015; Syvaka \& Ginoudi, 2013) and students can modify the content, correct their mistakes, and collaborate (Avci \& Askar, 2012; Geomelou, 2015; Mitala, 2008; Syvaka \& Ginoudi, 2013).

The implementation and use of the wiki for knowledge management depends on familiarizing trainers and trainees with technology, the degree of planning, the number of students and the teachers' ability to stimulate students (Chouliara et al., 2011; Notari, 2006; Raman, Ryan, \& Olfman, 2005).

In certain surveys on student participation in a web 2.0 platform, it was noted that there was some resistance to participation and collaboration on the wiki platform (Golikidou \& Tzimoyiannis, 2014) due to lack of motivation (Cole, 2009; Ebner, Kickmeier-Rust, \& Holzinger, 2008) and as a result of competition and insecurity (Guzdial, Ludovice, Realff, Morley \& Carroll, 2002; Kear, Woodthorpe, Robertson, \& Hutchison, 2010; Raitman, Augar, \& Zhou, 2005), which stemmed from the participants' lack of experience in collaborative environments (Guzdial et al., 2002; Manios, 2014) and the need for technical improvements to the wiki platform operations (Cole, 2009; Ebner et. al., 2008; Fu et al., 2013; Kear et al., 2010; Raitman et al., 2005), although there were no cases of participants attempting to alter content (Raitman et al., 2005). Meanwhile, there was difficulty in collaboration of students from different schools, participants preferred to work alone (Elgort et al., 2008; Engstrom \& Jewett, 2005; Hemmi et al., 2009) and the subject was approached superficially, except for the case of students in smaller groups, in which the results were positive (Engstrom \& Jewett, 2005).

\section{Theoretical Framework}

Collaborative learning has been incorporated into education to exploit the benefits of collaboration and to socialize trainees. There are two categories of cooperative learning approaches in the literature: The socio-constructivist approach, based on Piaget's theories and the socio-cultural approach, influenced by Vygotsky's theory through the prism of collective intelligence (Slavin, 1995, 1996).

According to Slavin (1995), learning based on collaboration involves techniques in which participants work and learn as team members to achieve a common goal. Johnson and Johnson (1975) focus on the concept of common goal as the prime feature of collaborative learning, while Dillenbourg (1999) distinguishes collaboration from 
cooperation.

Technology, as a cooperative mediator, should be seen not simply as a facilitator of collaborative learning but also as a factor that reforms human action. Therefore, mediative technology could transform the nature of collaboration. Consequently, technology has an effect on collaborative learning and can restructure it. It also offers the possibility to control the process of collaboration, the members' level of participation and the type of participation. Meaning, it records the contribution of each group member to the final product and to the process, making it possible to study the entire procedure and have access to feedback (Gianoutsou \& Trouki, 2008).

On the other hand, advancements in the field of cognition and cognitive development lead to the acceptance of the social character of learning and the framework for cognitive activity (Littleton \& Light, 1999). Thus, the creation of cooperative activities around and through the computer begins, as cognitive theory points to the need to design environments that facilitate interaction and collaborative learning (Brown \& Campione, 1996; Vosniadou, 1996), making the development of computer-supported collaborative learning inevitable. The first appearance of computer-supported collaborative learning took place in 1989, in a NATO workshop and today, it is one of the most prominent developing branches of Educational Technology (Karassavides \& Komis, 2008).

At the same time, Koschmann (1996) considers Computer Supported Collaborative Learning to be the fourth stage of the evolution of educational technology and integrates it into the social theories of social constructivism and socio-cultural theories. Lipponen and Lallimo (2004), in their attempt to find common points among successful examples of computer-assisted collaborative learning, emphasize on the role of designing the appropriate teaching method, on which cooperative technology will be based. They present the need for designed learning activities and emphasize the importance of the framework, the tool mediation and the practices followed (Karassavides \& Komis, 2008). In this approach, the educator is transformed from a knowledge authority into a student's counselor in the discovery, construction and sharing of knowledge (Marantos, 2001). An environment that implements CSCL enables students to take responsibility within the distinctive roles of a group. However, it requires a different culture in the classroom, as it supports knowledge through a different prism and requires a different approach from the teacher (Doyle, 1986).

Nowadays, Computer-Supported Collaborative Learning acquires new modern technological environments that mediate communication and support social interaction (Avouris, Dimitracopoulou, \& Komis, 2003), which are linked to the development of the internet and web 2.0 (Komis, 2004).

Web 2.0 technologies focus on users. They support student-centered teaching, as the wiki approach is a bottom-up approach. On wiki platforms, users are also writers and knowledge is shared, creating the right conditions for collaboration and interaction. The trainee from a passive receiver becomes an active creator and builds knowledge.

\section{Purpose and Research Questions}

The main purpose of this study, which is part of a wider research effort, is to investigate the effectiveness of Computer-Supported Collaborative Learning method's contribution in the teaching of Modern Greek Literature in Lyceum. In particular, the work aims to explore the contribution of the digital platform web 2.0 wiki pbworks - but also of subsidiary software and applications - to the teaching of Modern Greek Literature in Lyceum and to promote collaborative learning and the skills it cultivates among students.

The individual research questions that we'll attempt to answer are:

1) Can the use of an online, collaborative tool such as web 2.0 platform wiki pbworks enhance collaboration among students and consequently contribute to their skill development?

2) Are there any differences in the enhancement of collaboration and skill development between the students who used the wiki pbworks platform in their teaching, compared to students whose teaching was not supported by this tool?

\section{Methodology}

This paper presents some of the results of a broader research conducted in a public secondary school in the prefecture of Attica in December 2016. This study is a field experiment, with an Experimental Group and a Control Group. The experimental group was taught by the cooperative method and each group of students had a computer with an internet connection (workstation), while the control group was taught by the cooperative method without access to a computer. The survey was conducted from 10 October 2016 to 20 December 2016 and lasted thirteen teaching hours.

The sample selected for the experiment consists of fifty (50) second grade General Lyceum students in the prefecture of Attica. They are two of the six General Education classes of this particular Lyceum. They were 
selected as such, because Literature, which is the research field, is a General Education course. The researcher had at his disposal both the experimental team and the control group as a teacher in the specific classes. That is why these two classes (B1 and B2) of the second grade of the Lyceum were chosen to be used as a sample of the present study. Specifically, the twenty-five students (25) of the B1 class are the Experimental Group. The twenty-five (25) B2 class students are the Control Group. In the experimental group, there are 8 boys and 17 girls $(32 \%$ and $68 \%$, respectively). In the control group there are also 8 boys and 17 girls ( $32 \%$ and $68 \%$, respectively). The groups, therefore, are gender-equivalent, but the number of girls is superior. The age of the pupils varies between 16-17 years, as they are students of the second grade of Lyceum.

The two groups (experimental group and control group), are as equal as possible in terms of performance. In order to evaluate this, we took into account the students' performance in the course of Modern Greek Literature, as well as their overall performance during the previous school year. It should be noted that the grades of the previous year's grades were used as a criterion for assessing the pupils' initial school performance. The survey started in October, at the beginning of the new school year, therefore, those were the most recent indicators of their performance.

Web 2.0 platform, wiki pbworks as well as individual subsidiary tools (word processor, presentation software, video creating software, internet, browser software) are used as the main technology tools. More specifically, the research tools used in the context of this research are the following:

a. Student Activity Assessment Rubrics, which are completed by the teacher separately for each group and for each student after the experiment and the completion of the activities.

The activity assessment rubric used in this survey is an adaptation from: https://www.sandi.net/staff/i21-interactive-classroom/i21-interactive-classroom (Last recovered on 16/9/2016).

In detail, the teacher completes a Collaboration Assessment Rubric for each student in both the Experimental Group and the Control Group. Criteria relating to the educator's contribution to the team, responsibility, coverage of obligations etc. are also evaluated.

The conclusions of this rubric will be studied in conjunction with the self-assessment collaboration rubrics, completed by the students. The elements that will result from the comparison between the data of the assessment rubrics of the co-operation between students of the two groups, will be used to answer our second research question that explores the differentiation in broadening the co-operation among pupils and in cultivating the skills they develop among them as a result of this collaboration, among the pupils who used the wiki pbworks platform in their teaching, in relation to students whose teaching was not supported by this tool.

b. Student collaboration assessment rubrics, which are completed by the students of both groups before and after the didactic intervention to evaluate the collaboration. The collaboration assessment rubric used in this survey is an adjustment from:

https://www2.uwstout.edu/content/profdev/rubrics/secondaryteamworkrubric.html (last accessed on 4/9/2016).

More specifically, an assessment rubric of cooperation in the pre-evaluation phase was used in this research. It is filled out by the students before the experiment, in order to record their attitudes about cooperative teaching and group work. At the end of the experiment, in the evaluation process, the same rubric is given and filled out by the students. In particular, it is the self-assessment of students, always in relation to their attitude towards group teaching and work, after their participation in the experiment. The goal of using a double rubric assessment of student collaboration is to collect data that will answer our first research question whether the use of an online, collaborative tool such as a pbworks platform, which belongs to the web 2.0 category, contributes to widening co-operation between pupils and the cultivation of pupils' skills as a result of this collaboration.

In this survey, we tested Computer-Supported Collaborative Learning (CSCL) in the cross-curricular approach of teaching Modern Greek Literature in General Lyceum.

Research was carried out through the implementation of didactic intervention, in the form of a training scenario. The scenario is divided into three sections, which represent three different literary texts. It's based on the 5E Instructional Model (Bybee, 1997) founded on the constructivism-based Atkin, and Karplus (1962) model. Its purpose is to encourage students to enrich their initial thinking with additional knowledge and eventually change any misconceptions they have. Model $5 \mathrm{E}$ is divided into five learning phases: Engagement, Exploration, Explanation, Elaboration, Evaluation.

The research began when the pending appointment of teacher's was settled and the lesson timetable stabilized in the school unit where the study was conducted, and ended with the advent of December holidays, as the winter 
four-month course was completed. Although the investigation period was 2.5 months, the actual time of the research was relatively limited, thirteen hours in total. Finally, the subject matter of the course was relatively small, as it concerned the teaching of three literary texts.

\section{Results}

\subsection{Research Question 1: Attitudes of Experimental Group Students Related to Working in Groups (Before and After the Didactic Intervention)}

The participants completed a collaboration assessment rubric before the experiment was conducted. After the completion of the didactic intervention, the same collaboration assessment rubric was redistributed to the students. Their comparison would show any changes in the attitudes and views of students on collaboration.

The processing of the collaboration assessment rubric, which was completed by the students of the experimental group before the experiment, shows that, with a maximum rating of 60 points ( 12 criteria with a maximum of 5 for each), students gather from 34 (1 student) to 60 (1 student) points. The majority of students (15 students) gather from 46 to 52 points. More specifically, with a maximum score of 125 points ( 25 students * 5 points per proposal) the preference for cooperation scores 77 points, efficiency 89 points, confidence in cooperation 105 points, communication in teamwork 91 points, the contribution of ideas to the group 109 points, compliance with the rules of the dialogue 111 points, participation in the group 109 points, participation in the teamwork 103 points, the degree of cooperation with other members 103 points, the physical presence in the group during the project 91 points, motivating other members 101 points and attitude to problem solving 121 points.

The teacher filled out the collaboration assessment rubric by using the Recent Activity mode of wiki pbworks platform, which recorded each user's activity on the platform, but also by observing the students' activities in the classroom. The rubric's results show that, with a maximum score of 35 points ( 7 criteria with a maximum of 5 for each), the students gather from 17 (1 student) to 35 (5 students) points. More specifically, with a maximum score of 125 degrees ( 25 pupils $* 5$ points per criterion), collection of information gathers 95 points, 103 points for contribution of information to the group, 99 points for task performance, 95 points for participation in group assignments, 103 points for the degree of communication with group members, 107 points for conflict with other team members and 105 points for collaboration. The results of the collaboration assessment rubric, completed by the teacher, are presented per criterion in the table below (Table 1).

Table 1. Results of the collaboration assessment rubric of the experimental group during didactic intervention

\begin{tabular}{lccccc}
\hline \multirow{2}{*}{ Criterion } & Moderate & Good & Excellent & \multirow{2}{*}{ Score } \\
\cline { 2 - 5 } & 1 Point & 3 Points & 5 Points & \\
\hline Collection of information & 5 & 5 & 15 & 95 \\
Contribution of information to the group & 2 & 7 & 16 & 103 \\
Task performance & 1 & 11 & 13 & 99 \\
Participation in group assignments & 2 & 11 & 12 & 95 \\
Communication with group members & 0 & 11 & 14 & 103 \\
Conflict with other members of the group & 0 & 9 & 16 & 107 \\
Collaboration & 0 & 10 & 15 & 105 \\
\hline
\end{tabular}

After the didactic intervention was over, the students of the experimental group were distributed the same collaboration assessment rubric they had completed before the experiment had begun.

Comparing the experimental group students' results in collaboration assessment rubrics, before and after the experiment, there are differentiations, as shown by the percentage sign in the parentheses.

In detail, with a maximum score of 125 points ( 25 students $* 5$ points for each criterion) the collaboration rate increases from 77 points to 101 points after the experiment ( $+19 \%)$, the effectiveness moves from 89 to 93 points $(+3 \%)$, confidence in collaboration gathered 105 points before and 103 after the experiment $(-2 \%)$, communication during the group assignment increased from 91 to 103 points $(+9 \%)$, the contribution of ideas to the group gathered 109 points before and 117 after the intervention $(+7 \%)$, compliance with the rules of the dialogue noted 111 points before and 117 after $(+5 \%)$, participation in the group scored 109 points before and 119 after $(+8 \%)$, the degree of participation in the group assignment was rated with 103 points before and 115 after $(+$ $10 \%)$, the degree of cooperation with the other members gathered 103 points before and 105 after $(+2 \%)$, the physical presence in the group during the assignment increased from 91 to 105 points $(+11) \%)$, motivation of 
other members noted 101 degrees before and 119 after the experiment $(+14 \%)$ and the attitude towards problem solving was marked with 121 points before and 121 after the didactic intervention (0\%). The results of the students' answers in the assessment rubrics before and after the experiment, are presented comparatively in the following table. As can be seen from the table, the last two columns refer to the total score of the rubric before and after the didactic intervention (Table 2).

Table 2. Comparative presentation of the results of the experimental group students' responses in the collaboration assessment rubrics

\begin{tabular}{|c|c|c|c|c|c|c|c|c|}
\hline \multirow[t]{2}{*}{ Question } & \multicolumn{2}{|c|}{$\begin{array}{c}\text { Moderate } \\
1 \text { Point } \\
\end{array}$} & \multicolumn{2}{|c|}{$\begin{array}{c}\text { Good } \\
3 \text { Points }\end{array}$} & \multicolumn{2}{|c|}{$\begin{array}{c}\text { Excellent } \\
5 \text { Points }\end{array}$} & \multicolumn{2}{|c|}{$\begin{array}{c}\text { Score } \\
125 \text { Points }\end{array}$} \\
\hline & Before & After & Before & After & Before & After & Before & After \\
\hline \multirow{2}{*}{ Attitude towards collaboration } & 4 & 0 & 16 & 12 & 5 & 13 & 77 & 101 \\
\hline & $16 \%$ & 0 & $64 \%$ & $48 \%$ & $20 \%$ & $52 \%$ & $62 \%$ & $81 \%$ \\
\hline \multirow{2}{*}{ Effectiveness in group work } & 1 & 0 & 16 & 16 & 8 & 9 & 89 & 93 \\
\hline & $4 \%$ & $0 \%$ & $64 \%$ & $64 \%$ & $32 \%$ & $36 \%$ & $71 \%$ & $74 \%$ \\
\hline Confidence during & 2 & 0 & 6 & 11 & 17 & 14 & 105 & 103 \\
\hline collaboration & $8 \%$ & $0 \%$ & $24 \%$ & $44 \%$ & $68 \%$ & $56 \%$ & $84 \%$ & $82 \%$ \\
\hline Communication during group & 2 & 0 & 13 & 11 & 10 & 14 & 91 & 103 \\
\hline project & $8 \%$ & $0 \%$ & $52 \%$ & $44 \%$ & $40 \%$ & $56 \%$ & $73 \%$ & $82 \%$ \\
\hline Contribution of ideas to the & 1 & 0 & 6 & 4 & 18 & 21 & 109 & 117 \\
\hline group & $4 \%$ & $0 \%$ & $24 \%$ & $16 \%$ & $72 \%$ & $84 \%$ & $87 \%$ & $94 \%$ \\
\hline \multirow{2}{*}{$\begin{array}{l}\text { Compliance with the rules of } \\
\text { the dialogue in the group }\end{array}$} & 0 & 0 & 7 & 4 & 18 & 21 & 111 & 117 \\
\hline & $0 \%$ & $0 \%$ & $28 \%$ & $16 \%$ & $72 \%$ & $84 \%$ & $89 \%$ & $94 \%$ \\
\hline \multirow{2}{*}{$\begin{array}{l}\text { Participation in the group with } \\
\text { answers/ explanations }\end{array}$} & 0 & 0 & 8 & 3 & 17 & 22 & 109 & 119 \\
\hline & $0 \%$ & $0 \%$ & $32 \%$ & $12 \%$ & $68 \%$ & $88 \%$ & $87 \%$ & $95 \%$ \\
\hline \multirow{2}{*}{$\begin{array}{c}\text { Participation during group } \\
\text { assignment }\end{array}$} & 0 & 0 & 11 & 5 & 14 & 20 & 103 & 115 \\
\hline & $0 \%$ & $0 \%$ & $44 \%$ & $20 \%$ & $56 \%$ & $80 \%$ & $82 \%$ & $92 \%$ \\
\hline \multirow{2}{*}{$\begin{array}{l}\text { Collaboration with other group } \\
\text { members }\end{array}$} & 0 & 0 & 11 & 10 & 14 & 15 & 103 & 105 \\
\hline & $0 \%$ & $0 \%$ & $44 \%$ & $40 \%$ & $56 \%$ & $60 \%$ & $82 \%$ & $84 \%$ \\
\hline \multirow{2}{*}{$\begin{array}{l}\text { Physical presence in the group } \\
\text { during the assignment }\end{array}$} & 3 & 0 & 11 & 10 & 11 & 15 & 91 & 105 \\
\hline & $12 \%$ & $0 \%$ & $44 \%$ & $40 \%$ & $44 \%$ & $60 \%$ & $73 \%$ & $84 \%$ \\
\hline \multirow{2}{*}{ Motivation of other members } & 0 & 0 & 12 & 3 & 13 & 22 & 101 & 119 \\
\hline & $0 \%$ & $0 \%$ & $48 \%$ & $12 \%$ & $52 \%$ & $88 \%$ & $81 \%$ & $95 \%$ \\
\hline \multirow{2}{*}{$\begin{array}{l}\text { Attitude towards problem } \\
\text { solving }\end{array}$} & 0 & 0 & 2 & 2 & 23 & 23 & 121 & 121 \\
\hline & $0 \%$ & $0 \%$ & $8 \%$ & $8 \%$ & $92 \%$ & $92 \%$ & $97 \%$ & $97 \%$ \\
\hline
\end{tabular}

\subsection{Research Question 2: Differences in Collaboration Between the Students of the Two Groups}

Comparing the results of the collaboration assessment rubric, filled out by the teacher, for the experimental group and the control group (Table 3 ) shows that, with a maximum score of 125 points ( 25 pupils $* 5$ points per rubric criterion) shows the following outcomes: collection of information gathers 95 points for the experimental group and 91 for the control group, contribution of information of gathers 103 points for the experimental group and 95 for the control group, task performance collected 99 points for the experimental group and 91 for the control group, participation in group assignments noted 95 points for the experimental group and 99 for the control group, the degree of communication with other members scores 103 points for the experimental group and 123 for the control group, conflict with other group members gathered 107 points in the experimental group and 125 in the control group and cooperativeness reached 105 degrees for the experimental group and 123 for the control group. 
Table 3. Comparative presentation of collaboration assessment results between students of the experimental group and students of the control group

\begin{tabular}{ccc}
\hline & Experimental Group & Control Group \\
\hline Criterion & Score & Score \\
Collection of information & 95 & 91 \\
Contribution of information to the group & 103 & 95 \\
Task performance & 99 & 91 \\
Participation in group assignments & 95 & 99 \\
Communication with the rest of the group & 103 & 123 \\
Conflict with other members of the group & 107 & 125 \\
Collaboration & 105 & 123 \\
\hline
\end{tabular}

Comparing the results of the assessment rubric filled out by the students of both the experimental group and the control group (Table 4) shows that the positive attitude towards cooperation differs after the didactic intervention; $+19 \%$ for the experimental group and $+2 \%$ for the control group. The degree of efficiency after the didactic intervention increases by $+3 \%$ for the experimental group and $+6 \%$ for the control group. Confidence during collaboration after the didactic intervention decreases by $-2 \%$ for the experimental group and $-2 \%$ for the control group. The communication during group assignments after the completion of the experiment increases by $+9 \%$ for the experimental group and $+3 \%$ for the control group. The contribution of ideas to the group after the didactic intervention is higher by $+7 \%$ for the experimental group and $+3 \%$ for the control group. Compliance to the rules of the dialogue differs after the didactic intervention increasing by $+5 \%$ for the experimental group and $0 \%$ for the control group. The degree of participation after the experiment is $+8 \%$ for the experimental group and $0 \%$ for the control group. The degree of participation during group projects is increased by $+10 \%$ for the experimental group and $+5 \%$ for the control group. Collaborating with the other group members after the didactic intervention is higher by $+2 \%$ for the experimental group and $+10 \%$ for the control group. The physical presence in the group during the project is different after the intervention by $+11 \%$ for the experimental group and by $+8 \%$ for the control group. Motivation of other group members, after the experiment is $14 \%$ higher for the experimental group and $0 \%$ for the control group. The attitude to problem solving after the didactic intervention is $0 \%$ in the experimental group and $0 \%$ in the control group. 
Table 4. Comparative presentation of collaboration assessment results between students of the experimental group and students of the control group

\begin{tabular}{|c|c|c|c|c|}
\hline \multirow[t]{2}{*}{ Question } & \multicolumn{2}{|c|}{$\begin{array}{c}\text { Experimental Group } \\
\text { Score } \\
125 \text { Points } \\
\end{array}$} & \multicolumn{2}{|c|}{$\begin{array}{c}\text { Control Group } \\
\text { Score } \\
125 \text { Points } \\
\end{array}$} \\
\hline & Before & After & Before & After \\
\hline \multirow{2}{*}{ Attitude towards collaboration } & 77 & 101 & 99 & 101 \\
\hline & $62 \%$ & $81 \%$ & $79 \%$ & $81 \%$ \\
\hline \multirow{2}{*}{ Effectiveness in group work } & 89 & 93 & 85 & 93 \\
\hline & $71 \%$ & $74 \%$ & $68 \%$ & $74 \%$ \\
\hline \multirow{2}{*}{ Confidence during collaboration } & 105 & 103 & 105 & 103 \\
\hline & $84 \%$ & $82 \%$ & $84 \%$ & $82 \%$ \\
\hline \multirow{2}{*}{ Communication during group assignments } & 91 & 103 & 99 & 103 \\
\hline & $73 \%$ & $82 \%$ & $79 \%$ & $82 \%$ \\
\hline \multirow{2}{*}{ Contribution of ideas to the group } & 109 & 117 & 115 & 119 \\
\hline & $87 \%$ & $94 \%$ & $92 \%$ & $95 \%$ \\
\hline \multirow{2}{*}{ Acceptance of criticism from the group } & 111 & 117 & 117 & 117 \\
\hline & $89 \%$ & $94 \%$ & $94 \%$ & $94 \%$ \\
\hline \multirow{2}{*}{ Participation in the group with answers/explanations } & 109 & 119 & 117 & 117 \\
\hline & $87 \%$ & $95 \%$ & $94 \%$ & $94 \%$ \\
\hline \multirow{2}{*}{ Participation in the group project } & 103 & 115 & 99 & 105 \\
\hline & $82 \%$ & $92 \%$ & $79 \%$ & $84 \%$ \\
\hline \multirow{2}{*}{ Collaboration with the rest of the group } & 103 & 105 & 55 & 101 \\
\hline & $82 \%$ & $84 \%$ & $44 \%$ & $81 \%$ \\
\hline \multirow{2}{*}{ Physical presence during the project } & 91 & 105 & 91 & 101 \\
\hline & $73 \%$ & $84 \%$ & $73 \%$ & $81 \%$ \\
\hline \multirow{2}{*}{ Motivation of other members } & 101 & 119 & 115 & 115 \\
\hline & $81 \%$ & $95 \%$ & $92 \%$ & $92 \%$ \\
\hline \multirow{2}{*}{ Attitude to problem solving } & 121 & 121 & 119 & 119 \\
\hline & $97 \%$ & $97 \%$ & $95 \%$ & $95 \%$ \\
\hline
\end{tabular}

\section{Discussion}

\subsection{Research Question 1}

The conclusion drawn from the observation of the collaboration assessment rubric's results of the students of the experimental group, which was filled out by the teacher, is that pupils' development of collaboration skills, as members of their teams, was good to excellent in all the criteria, as scores ranged from 95/125 points to 107/125 points.

The comparison of the collaboration assessment rubric, filled out by the students of the experimental group before and after the didactic intervention, shows that, after the experiment, the attitude towards collaboration is a lot more positive, while the efficiency shows less of an increase. At the same time, students communicate more within their groups, contribute with more ideas, follow the rules of dialogue to a higher degree, participate more in the group and in their project, work more closely, are present in the group, and motivate other members more. Their attitude to problem solving remains steadily high, while confidence in collaboration presents a slight decrease.

The result is in line with the literature, since, according to Kassotakis and Flouris (2006), surveys conducted in the USA have shown, amongst other positive findings for computer learning, that it also encourages collaborative learning and sociability among students, because it facilitates the exchange of information and creates conditions for teamwork. Meanwhile, web 2.0 technology takes the concept of collaboration to new dimension, adding to live communication and also to the remote synchronous and asynchronous communication (Avouris et al., 2008). At the same time, it's in accordance with the study by De Wever et al., (2015), which found important positive elements related to collaborative group activities and students' feelings of shared responsibility

\subsection{Research Question 2}

The comparison of the collaboration assessment rubric's results of both the students of the experimental and the control group, conducted by the teacher, shows that the experimental group achieved a slightly higher score than 
the control group but a lower overall score.

Comparing the results of the collaboration assessment rubrics, which were completed by students of both teams before and after the didactic intervention, pointed out that the experimental group presents a fairly high positive attitude on cooperation, unlike the control group, whose opinions towards collaboration were positive, but to a much lesser extent. Specifically, the variation in the experimental group ranged from $2 \%$ to $19 \%$ per criterion, while the control group differentiation ranged from $2 \%$ to $8 \%$ per criterion. It is also worth mentioning that the views of the students of both groups differ negatively, from $84 \%$ to $82 \%$, only on the criterion of confidence towards collaboration.

The result is in line with the research by $\mathrm{Fu}$ et al. (2013), according to which, the wiki platform provided educational, technological and social opportunities for collaborative learning among students.

\section{Conclusions}

As far as the first research question is concerned, after the conduction of the experiment, the experimental group students tend to cooperate much more than they used to. They communicate effectively, share their ideas with the other members of the group, and comply to the rules of dialogue much more than before the didactic intervention. They participate within their group, they always complete their assignments, let the others do their share of work and stay firm in the team more than before the experiment. They encourage the other members of the team much more vividly than before the didactic intervention and remain firm in their intention to help solve problems in the group. Therefore, the use of the digital web 2.0 platform, wiki pbworks, helps increase student collaboration, both inside and outside the school environment.

Comparing the rubric results, filled out by the teacher, of the experimental group with those of the control group, it was found that the control group had a more positive attitude towards collaboration as a whole, although they fell short in certain criteria. Additionally, from the comparison of the results of the collaboration rubric, completed by the students of the experimental group before and after the experiment, with those completed by the students of the control group before and after the didactic intervention, it was found that the students of the experimental group show a higher positive differentiation in their views regarding collaboration compared to the control team. Meanwhile, the views of the control group concerning collaboration are also more positive than before. Both groups, in other words, transform their views on the most positive towards collaboration; hence, they're positive for a school group project as a teaching method. Changes, however, are not the same for both groups. In the experimental group, the differentiation is very high, while in the control group it's relatively small.

Therefore, the implementation of the collaborative method with the support of a computer with Internet access and digital collaboration web 2.0 platform, wiki, pbworks developed more positive attitudes among experimental group students towards collaboration and skills developed through this approach, in relation to teaching with the collaborative method without a computer, which was the way the control group was taught.

\section{Suggestions-Constraints}

Despite the positive results from using the web 2.0 platform (wiki pbworks) aiming to develop student collaboration, there are some limitations worth mentioning. The sample of the survey, which consisted of 50 students, was relatively small. Using a larger sample would reinforce the credibility of the survey. At the same time, there were time constraints which did not allow further duration of the research program. Finally, as in every survey, the participants, in this case students, may not have been completely honest in their responses of their experience, linking the conduct of the survey to sitting an exam.

The constraints mentioned earlier in the chapter of methodology lead to the following suggestions for further research. The present research was conducted only in the teaching of the Literature course to students of the second grade of Lyceum. Future studies could examine the effectiveness of the web 2.0 platform (wiki pbworks) in the teaching of other subjects to students of smaller and / or older classes. In addition, future surveys could use a combination of quantitative and qualitative approaches, and more specifically to conduct personal interviews with students, teachers, and students' parents.

In addition, the sample, as mentioned, consisted, in both groups, of nine boys and sixteen girls. The fact that the number of girls was twice that of boys could have influenced the results of the survey. It would be interesting to have a similar investigation in a sample with an equal number of boys and girls.

The next phase could be the setting up of a more extensive program of interventions, which, other than lasting longer, will also include teaching in more cognitive subjects. The implementation of such a program in more classes and the comparative study of the data should provide a more complete picture of the effectiveness of the web 2.0 platform (wiki pbworks) regarding other aspects of the didactic-learning process, such as the exploration 
of its contribution to the mobilization of students, the development of more positive attitudes towards school and learning as a result of its implementation, and others.

It would also be interesting to further examine this topic by using another online collaboration tool to determine the value of the tool used in this study by comparing them.

\section{References}

Altanopoulou, P. (2011). Evaluating the learning effectiveness of educational activities using wikis. Didactics of Science: Educational Programs, Evaluation and Information and Communication Technologies in Education (MA thesis, Department of Educational Sciences and Early Childhood Education. Patras: University of Patras).

Atkin, J., \& Karplus, R. (1962). Discovery or Invention? The Science Teacher, 29(5), 45-51. Retrieved from http://www.jstor.org/stable/24146536

Avci, U., \& Askar, P., (2012). The Comparison of the Opinions of the University Students on the Usage of Blog and Wiki for Their Courses. Journal of Educational Technology \& Society, 15(2), 194-205. Retrieved from http://www.jstor.org/stable/jeductechsoci.15.2.194

Avouris, N., Dimitracopoulou, A., \& Komis, V. (2003). On Analysis of Collaborative Problem Solving: An Object-Oriented Approach. Computers in Human Behavior, 19(2), 147-167. https://doi.org/10.1016/S0747-5632(02)00056-0

Avouris, N., Karagianidis, X., \& Komis, V. (2008). Collaborative Technology: Systems and Collaboration Models for Working, Learning, Communities of Practice and Creation of Knowledge. Athens: Klidarithmos.

Brown, A., \& Campione, J. (1996). Psychological theory and the design of innovative learning environments: On procedures, principles, and systems. In L. Schauble, \& R. Glaser (Eds.), Innovations in learning: New environments for education (pp. 289-325). Mahwah, NJ: Lawrence Erlbaum Associates, Inc.

Bybee, R. W. (1997). Achieving scientific literacy: From purposes to practices. Portsmouth, NH: Heinemann.

Cho, M.-H., \& Lim, S. (2017). Using regulation activities to improve undergraduate collaborative writing on wikis. Innovations in Education and Teaching International, 54(1), 53-61. https://doi.org/10.1080/14703297.2015.1117009

Chouliara, O., Frentzou-Rodokanaki, M., \& Antoniou, K. (2011). The use of wikis in the classroom: the asynchronous education course. In 6th International Conference in Open \& Distance Learning. eProceedings, 6(2B). Loutraki: Greece. https://doi.org/10.12681/icodl.656

Cole, M. (2009). Using Wiki technology to support student engagement: Lessons from the trenches. Computers and Education, 52(1), 141-146. https://doi.org/10.1016/j.compedu.2008.07.003

De Wever, B., Hämäläinen, R., Voet, M., \& Gielen, M. (2015). A wiki task for first-year university students: The effect of scripting students' collaboration. Internet and Higher Education, 25, 37-44. https://doi.org/10.1016/j.iheduc.2014.12.002

Dillenbourg, P. (1999). What do you mean by collaborative learning? In P. Dillenbourg (Ed.), Collaborative-learning: Cognitive and Computational Approaches (pp. 1-19). Oxford.Elsevier.

Doyle, W. (1986). Classroom management techniques and students discipline. Handbook of Research on Teaching, 392-431. https://doi.org/10.1007/s13398-014-0173-7.2

Ebner, M., Kickmeier-Rust, M., \& Holzinger, A. (2008). Utilizing Wiki-Systems in higher education classes: A chance for universal access? Universal Access in the Information Society, 7(4), 199-207. https://doi.org/10.1007/s10209-008-0115-2

Elgort, I., Smith, A. G., \& Toland, J. (2008). Is wiki an effective platform for group course work? Australasian Journal of Educational Technology, 24(2), 195-210. https://doi.org/10.14742/ajet.1222

Engstrom, M. E., \& Jewett, D. (2005). Collaborative learning the wiki way. TechTrends, 49(6), 12-15. https://doi.org/10.1007/BF02763725

Fu, H., Chu, S.\& Kang, W. (2013). Affordances and Constraints of a Wiki for Primary-school Students' Group Projects. Journal of Educational Technology \& Society, 16(4), 85-96. Retrieved from http://www.jstor.org/stable/jeductechsoci.16.4.85

Geomelou, A. (2015). Development of creativity in a digital collaborative learning environment to solving authentic problems. Thesis. MA "Teaching of Technology \& Digital Systems". Department of Digital 
Systems. Piraeus: University of Piraeus.

Gianoutsou, N. \& Trouki, E. (2008). The Role of Technology in Reorganizing and Enhancing Collaboration. In N. Avouris, Ch. Karagiannidis, \& V. Komis (Rds.), Collaborative Technology, Systems and Models of Collaboration for Working, Learning, Communities of Practice and Creation of Knowledge. Athens: Klidarithmos.

Golikidou, L., \& Tzimoyiannis, A. (2014). Educational Innovations in Secondary Education: Design and study of an eLearning program within the Comenius project. Science and Technology Issues in Education, 7(1-2), 99-118.

Guzdial, M., Ludovice, P., Realff, M., Morley, T., \& Carroll, K. (2002). When Collaboration Doesn't Work. Fifth International Conference of the Learning Sciences (May 2017). Georgia Institute of Technology. Atlanta.

Hemmi, A., Bayne, S. \& Land, R. (2009), The appropriation and repurposing of social technologies in higher education. Journal of Computer Assisted Learning, 25, 19-30. https://doi.org/10.1111/j.1365-2729.2008.00306.x

Jeong, H., Hmelo-Silver, C. E., Jo, K., \& Shin, M. (2016). CSCL in STEM education: Preliminary findings from a meta-analysis. Proceedings of the Annual Hawaii International Conference on System Sciences, 2016-March(April), 11-20. https://doi.org/10.1109/HICSS.2016.11

Johnson, D., \& Johnson, R. (1975). Learning together and alone, cooperation, competition, and individualization. Boston: Allyn \& Bacon.

Karassavides I., \& Komis, V., (2008) Theoretical Issues to Support Collaboration and Learning. In N. Avouris, Ch. Karagiannidis, \& V. Komis (Eds.), Collaborative Technology, Systems and Models of Collaboration for Working, Learning, Communities of Practice and Creation of Knowledge. Athens: Klidarithmos.

Karystinakis, I. (2012). The use of wikis for the teaching of computer science in secondary education. Thesis. MA "Didactics of Technology \& Digital Systems". Department of Digital Systems. Piraeus: University of Piraeus.

Kassotakis, M., \& Flouris, G. (2006). Learning and Teaching (Vol. b). Athens: Grigoris.

Kear, K., Woodthorpe, J., Robertson, S., \& Hutchison, M. (2010). From forums to wikis: Perspectives on tools for collaboration. Internet and Higher Education, 13(4), 218-225. https://doi.org/10.1016/j.iheduc.2010.05.004

Komis, V. (2004). Introduction to the educational applications of information and communication technologies. Athens: New Technologies Publishing.

Koschmann, T. (1996). Paradigm shifts and instructional technology. In T. Koschmann (Ed.), CSCL: Theory and practice of an emerging paradigm (pp. 1-23). Mahwah, NJ: Lawrence Erlbaum.

Kyrtsoglou, A. (2009). Creating a web 2.0 environment for Collaborative Knowledge Development. Interdepartmental Thesis. MA in Information Systems. Thessaloniki. University of Macedonia.

Lipponen, L., \& Lallimo, J. (2004). From Collaborative Technology to Collaborative Use of Technology: Designing Learning Oriented Infrastructures. Educational Media International, 41(2), 111-116. https://doi.org/10.1080/09523980410001678566

Littleton, K., \& Light, P. (1999). Learning with Computers: Analysing Productive Interactions. Journal of Computer Assisted Learning, 15(4), 332. Published by Routledge. https://doi.org/10.4324/9780203282311

Manios, S. (2014). The use of Wiki as a Collaborative e-learning tool: Case study in vocational high school. Institutional Repository Kypseli. Open University of Cyprus.

Marantos, P. (2001). Education and Mass Media. Athens: Patakis.

Mitalas, A. (2008). Teaching using new technologies: Artificial Intelligence, web 2.0: Blogs- wiki - webquest. (MA Thesis in Educational Sciences - Training using New Technologies, Department of Primary Education, University of the Aegean(.

Neumann, D. L., \& Hood, M. (2009). The effects of using a wiki on student engagement and learning of report writing skills in a university statistics course. Australasian Journal of Educational Technology, 25(3), 382-398. https://doi.org/10.14742/ajet.1141

Notari, M. (2006). How to use a Wiki in education. Proceedings of the 2006 International Symposium on Wikis WikiSym '06, 131. https://doi.org/10.1145/1149453.1149479 
Pozidis, P. \& Manousou, E., Koutsouba, M. (2015). Collaborative learning in the context of complementary distance learning in a network of primary schools in Corfu. 8th International Conference in Open \& Distance Learning Proceedings 8 (1A). Athens, Greece. https://doi.org/10.12681/icodl.40

Raitman, R., Augar, N., \& Zhou, W. (2005). Employing Wikis for Online Collaboration in the E-Learning Environment: Case Study. Third International Conference on Information Technology and Applications (ICITA'05), 2(July), 142-146. https://doi.org/10.1109/ICITA.2005.127

Raman, M., Ryan, T., \& Olfman, L. (2005). Designing Knowledge Management Systems for Teaching and Learning with Wiki Technology. Journal of Information Systems Education, 16(3), 311-320.

Rick, J., Guzdial, M., Holloway-Attaway, K. C. L., \& Walker, B. (2002). Collaborative learning at low cost: CoWeb use in English composition. Proceedings of the Conference on Computer Support for Collaborative Learning: Foundations for a CSCL Community, 435-442. https://doi.org/10.3115/1658616.1658677

Roussinos, D. \& Tzimoyiannis, A. (2011). Design and study of a mixed e-learning environment through wiki: A case study on first-year university students. 6th International Conference Open \& Distance Learning. eProceedings, 6(2B). Loutraki. Greece. https://doi.org/10.12681/icodl.663

Ruth, A., \& Houghton, L. (2009). The wiki way of learning. Australasian Journal of Educational Technology, 25(2), 135-152. https://doi.org/10.14742/ajet.1147

Slavin R. E. (1995). Cooperative learning: Theory, research, and practice (2nd ed.). Boston: Allyn \& Bacon.

Slavin, R. (1996). Research for the Future. Research on Cooperative Learning and Achievement: What We Know, What We Need to Know. Contemporary Educational Psychology, 69(1), 43-69. https://doi.org/10.1006/ceps.1996.0004

Syvaka, T. \& Ginoudi, A. (2013). The Contribution of "Social" Web 2.0 Tools to Building Collaborative Knowledge. 7th International Conference in Open \& Distance Learning. eProceedings, 7(2B). Athens. Greece. https://doi.org/10.12681/icodl.647

Vosniadou, S. (1996). Towards a revised cognitive psychology for new advances in learning and instruction. Learning and Instruction, 6(2), 95-109. https://doi.org/10.1016/0959-4752(96)00008-4

Wang, Y. C. (2014). Using wikis to facilitate interaction and collaboration among EFL learners: A social

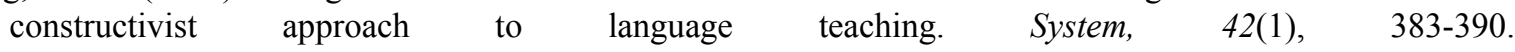
https://doi.org/10.1016/j.system.2014.01.007

\section{Copyrights}

Copyright for this article is retained by the author(s), with first publication rights granted to the journal.

This is an open-access article distributed under the terms and conditions of the Creative Commons Attribution license (http://creativecommons.org/licenses/by/4.0/). 